\title{
Mathematics Learning Tools Development Based on Problem Based Learning (PBL) to Increase Students Problem Solving Ability in Senior High School
}

\author{
$1^{\text {st }}$ Reni Septriwati \\ Mathematics Department \\ Universitas Negeri Padang \\ Padang, Indonesia \\ reniseptri10@gmail.com
}

\author{
$2^{\text {nd }}$ I Made Arnawa \\ Mathematics Department \\ Universitas Andalas \\ Padang, Indonesia \\ arnawa1963@gmail.com
}

\author{
$3^{\text {rd Atmazaki }}$ \\ Faculty of Lingustics and Arts \\ Universitas Negeri Padang \\ Padang, Indonesia
}

\begin{abstract}
This research is a development research using Plomp model which consists of three phases that are initial investigation phase, development and assessment. Devices developed RPP and LKPD based Problem Based Learning (PBL) to improve problem solving skills. Learning devices are tested in high school class XI students. Based on the results of the analysis, it can be concluded that the learning device of mathematics are valid, practical and effective.
\end{abstract}

Keywords-Problem Based Learning, Problem Solving Abilities, Plomp Development Model

\section{INTRODUCTION}

The ability to solve problems also determine the success or failure of mathematics learning. Not only that, but learners also gain a way of thinking, persistence, curiosity and confidence [1]. Recognizing the purpose and role of learning mathematics, it is required an effective and meaningful learning for students. Mathematics learning is a teacher-student interaction activity, students- students, and teacher-students to clarify the mind and understanding of a given mathematical idea through logical, categorical and systematic thinking and action [2]. Therefore learners need to understand and master the math so that the various competencies are expected to be achieved properly and optimally. However, reality shows that the ability of problem solving mathematics owned by learners in Indonesia is still relatively low. Based on the results of TIMSS (Trends International Mathematics Science Study) in 2015 it is known that Indonesia is ranked 45 out of 50 countries only $2 \%$ at high level, and $0 \%$ in advance level. While the results of the PISA survey in 2015, Indonesia position is on 63 out of 69 countries in mathematics.

The low ability to solve mathematical problems of students is also seen in one of the schools such as SMA Negeri 1 Pancung Soal. From the observations and interviews conducted with teachers of mathematics in SMA Negeri 1 Pancung Soal on 07-21 August 2017, it is known that there are still many students who have not been able to solve math problems. To understand and apply to new things, the learners need to develop problem solving skills, so that learners are accustomed to think scientifically in everyday life [3]. Most learners cannot make a connection between what they learn and how the knowledge will be applied in their lives.

The learners looks confused how to deal the problem in the form of a story. To solve the problem the learners directly answer what is associated with the formula, and immediately apply the formulas. Learners are faced with a problem as a stimulus that encourages learners to use knowledge to analyze problems [4]. Learners do not know the existence of a concept link with another concept. This indicates that learners do not have the ability to solve problems and confidence in solving the problem. Learning uses real-world problems as a context for learners to learn about thinking and problem-solving skills, and to acquire essential knowledge and concepts from instructional materials [5].

Low ability in mathematics problem solving can be seen from how the learners answer the problem Figure 1.

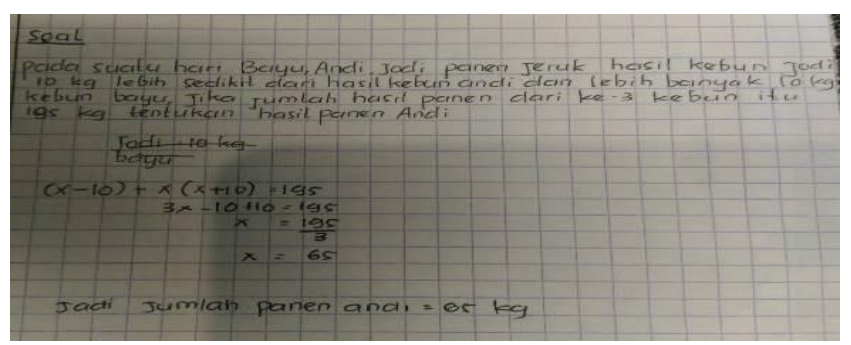

Figure 1. Examples of learners' answers.

The learner directly answers the problem without identifying the elements that are known and asked (Figure 1). The mathematical model which compiled with the entire problem is applied incorrectly so that the results obtained are also wrong.

Based on interviews with mathematics teachers, it is also known that the teachers have attempted to apply learning models that can motivate and enable learners in the learning process. However, learning objectives have not been achieved because of the low ability in problem solving. Teachers have not created and developed instructional materials in accordance with Candidate No. 24 that can facilitate learners in solving problems because teachers still depend on the text book and even then not sufficient as 
many existing learners as well as teachers have not made LKPD itself.

A good LKPD has a complete and clear material. LKPD contains questions, especially varied questions in order to improve the problem solving of mathematical learners. While learners only use LKPD bought outside the contents of minimal material the given problem also does not present a contextual problem that stimulates learners to learn. Problem-based LKPD results in the interaction of learners with teachers and learners with learners who make learning more interesting and fun [6].

Along with the need for LKPD that can support problem-solving ability, it is necessary for a foundation in developing RPP and LKPD. RPP and LKPD are more optimal if they are based on one of the learning models that aim to improve the problem solving ability of learners and teach the students how to solve a problem. One of the learning models used to achieve these goals is through the model of learning Problem Based Learning or abbreviated PBL.

The PBL learning model begins with contextual, nonroutine or open-ended problems. The problem will be solved through a series of activities such as finding / identifying problems, gathering facts, preparing hypotheses, conducting investigations, refining defined problems and summarizing alternative problem solving. PBL is a way that focuses on activities to empower learners to integrate theory, apply knowledge and to develop their own solution-finding skills [7]. These activities will help learners to work through the problem in a systematic way to reach the problem solving ability of the learners.

Phases of activities undertaken in the PBL can also indicate the achievement of indicators of problem-solving abilities. The first phase of the student's orientation to the problem, in this phase the learner understands the problem in LKPD and identifies the elements known, inquired, and the adequacy of the elements needed to answer the problem. The second phase organizes learners to learn, in this phase learners formulate mathematical problems. Phase three develops and presents the work, in this phase learners apply strategies to solve various problems. The last phase analyzes and evaluates the problem-solving process, in this phase the learner interprets the results according to the original problem.

The development RPP and LKPD based on PBL is limited to be implemented in the grade XI of SMA in the second Semester. Based on the above, the development of RPP and LKPD is hopefully achieved in our research entitled "Development of Learning Mathematics Based Problem Based Learning (PBL) to Improve Mathematical Problem Solving Ability in Grade XI Senior High School".

\section{METHODS}

The type of this research is a development research using the Plomp model, starting from the preliminary research phase, the prototyping stage, and the assessment phase [8]. To obtain valid PBL-based learning tools, a preliminary research is conducted. Based on the analysis results in the preliminary research phase, PBL-based learning tools are designed. The preliminary research phase consists of needs analysis, curriculum analysis, learner analysis and concept analysis. In the development or prototype phase (development or prototyping phase) designed learning tools based on PBL. In the prototyping stage, the formation of prototypes is done by formative evaluation. The prototyping stage consists of prototype 1 , self evaluation and expert review; prototype 2, ie one-to-one evaluation; prototype 3 , ie small group evaluation, and prototype 4 which is the result of formative evaluation. The PBL-based learning tools that have been designed are self-evaluated and validated by expert review. Validation of the device is done by three lecturers of Mathematics, one lecturer of Education Technology and one lecturer of Bahasa. Once a valid PBLbased learning tool is produced, one-to-one, small group and field test evaluations are used for practicality. In the assessment phase, a field test was conducted in grade XI IPA SMA 1 Pancung Soal to see the practicality and effectiveness. The research data was collected through validation sheet, teacher's and student's response questionnaire, valid observation sheet of RPP, interview sheet, and test result of problem solving ability of learner.

\section{RESULTS AND DISCUSSION}

\section{Initial Investigation Phase}

Activities in the initial investigative phase begin with needs analysis, curriculum analysis, learner analysis and concept analysis. Description of the results of the initial investigative phase.

\section{a. Needs Analysis}

Based on the results of interviews and observations made with mathematics teachers SMA Negeri 1 Pancung Soal, obtained some information. That is, teachers have attempted to apply learning models that can motivate and enable learners in the learning process. However, learning objectives have not been achieved because of the low ability in problem solving.. To answer the problem, learners directly answer what is associated with the formula, and immediately apply the formula that is known. This suggests that learners do not have the ability to solve problems and confidence in solving problem.

Besides conducting interviews and observations, researchers also conducted questionnaires to 31 learners about the characteristics of LKPD. Based on the result of the questionnaire, it can be concluded that the desired LKPD is quite interesting, the paper size used is A4 size paper, and it is accompanied by illustration of the picture in accordance with the material and increase the attractiveness of LKPD.

\section{b. Curriculum Analysis}

At this stage, a review of the 2013 curriculum for compulsory mathematics subjects of grade XI is consisted of sequence and material, material function limit, derivative material and integral material contained in the syllabus. This analysis serves as a guide in developing LKPD based on Problem Based Learning (PBL). Analysis for the basic competence of this material is the development of indicators by using Problem Based Learning (PBL) based on learning to organize the material and determine the learning objectives to be achieved at each meeting. In this study Core Competence and Basic Competence mathematics subjects are taken Derived material. 


\section{c. Analysis of Learners}

Analysis of learning tendencies, attitudes, skills, cooperative skills, social skills is obtained through direct observation when teaching in the classroom. First is learners prefer to do learning activities through peer tutor. This is seen when the learning process takes place, if learners do not understand the material taught by the teacher, then most of the participants prefer to ask questions with friends. Both learners prefer to group in doing something activity. When the teacher gives the exercises, learners prefer to do the exercises together with their friends instead of doing it on their own. This character indicates that learners prefer to do an activity together. Based on the interview it is also known that most learners live near the river, near the market, the area of the palm oil factory and coastal areas that cause learners have a more daring character, so familiarize students also dare to appear in front of the class. Based on the results of characteristic analysis of learners can be concluded that most learners prefer group discussions.

\section{d. Concept Analysis}

Concept analysis aims to determine the materials needed in the development of learning tools to achieve indicators of achievement of competence. The required material is about Derivative, stationary point, descending function and rising function. The results of this concept analysis become the basis in the design of RPP and LKPD based on Problem Based Learning.

\section{Phase Development or Making Prototype}

\section{a. Designing Learning Tools}

Designing learning tools based on PBL learning based on analysis in the initial investigative phase. The result of this design will produce prototype 1. Learning device is designed to refer to PBL learning characteristic. The following description of learning tools based on PBL learning.

\section{1) Designing RPP}

RPP is designed as a guide for teachers in implementing the learning process. RPP components are designed based on Permendikbud No. 103 Year 2014. Learning activities presented in the RPP refers to the learning based Problem Based Learning integrated with the use of LKPD based Problem Based Learning. Presentation of RPP's identity, competency standard, basic competence, competency achievement indicator, learning objectives, learning materials, approaches, models, learning methods, time allocation, learning activities, learning resources and assessment are similar to RPP in general. RPP components that are characteristic of RPP based Problem Based Learning, among others, can be observed in the steps of learning activities.

The core activities of RPP are based on PBL-based learning syntax. PBL learning begins with the orientation stage of learners on the problem. This stage of the learner is faced with a problem related to the concept to be studied. The second stage of PBL learning is organizing learners. At this stage learners understand and examine the problems so that learners can understand the concepts learned. The third stage of PBL learning is guiding individual and group investigations. At this stage learners are trained to issue ideas in discussions and appreciate the opinions of friends in other groups. Learners are invited to be able to solve problems related to daily life associated with Derivatives. Exercise questions given to LKPD make learners better understand the concept of lessons in more depth and meaningful, so the concept learned is easy to remember. The fourth stage is to develop and present the work. At this stage learners present their group discussion results. The fifth stage is to analyze and evaluate the problem-solving process. At this stage learners respond to the results that are displayed by their friends.

\section{2) Designing LKPD}

LKPD-based PBL has several components namely title, $\mathrm{KD}$, LKPD instructions, learning objectives, problems, work steps, exercises. LKPD has interesting pictures in accordance with the given problem to understand the concept learned. LKPD is designed with a variety of colors and bright. LKPD begins by presenting questions or problems that aim to help learners to relate observed phenomena to the concepts to be constructed. Furthermore, to train the problem-solving skills of the learner, identify the identified elements, questions, and adequacy of the necessary elements, formulate the problem, solve the problem, draw conclusions and re-examine the results obtained. LKPD uses simple and communicative language and in accordance with the communication level of learners, so that the presentation of the material on LKPD can be understood well. The questions in LKPD are arranged with clear sentences so as to lead learners to get the expected answers.

\section{b. Self evaluation}

The result of the design of a learning device called prototype 1 is done by self evaluation first to the learning device that has been designed before it is validated. There are three main aspects that are evaluated in RPP, namely typing errors, completeness of RPP components, and the accuracy of writing size. In LKPD, there are three aspects that are evaluated namely typing errors, less obvious sentences meaning, and the availability of empty space to solve the problem or answer the question.

In general, many errors occur in typing words and punctuation. For example, an error occurs on the word "straight line" written "without spaces", "gradient" written "gadien", and others. In addition, there are also less precise punctuation, the command line is marked with a period, should be marked commands / exclamation points. In addition the researchers also estimated the adequacy of empty space in LKPD as a place of students to write answers.

After the self-evaluation, a revision of the learning device is made. Then the results of prototype 1 consulted and discussed with experts who are competent to be validated

\section{c. Experimental Tool Validation Results by Experts}

Learning tools validated by 5 validators are 3 mathematics lecturers, 1 lecturer of educational technology and 1 lecturer of Indonesian language. In the RPP aspects observed are aspects of RPP identity, indicators of competency achievement, learning objectives, teaching 
materials, models, approaches, strategies and learning methods, learning activity steps, learning resources, assessment, writing language, and RPP benefits.

The overall validity of RPP is $92.5 \%$ with very valid category. Thus, it can be concluded that the aspect of the PBL based RPP component is valid.

In LKPD aspects observed are aspects of didactic or presentation, material and content aspects, linguistic aspects, and aspects of chart or appearance. The validity value of LKPD in the aspect of presentation and feasibility of each content is $87,5 \%$ and $88,25 \%$. Thus, it can be concluded that LKPD has been valid from aspects didactic and material aspects.

LKPD validation on linguistic aspect is done by 1 lecturer of Indonesian language at the same time. LKPD validity case value is $88.25 \%$ with valid criteria. Validation results illustrate that the use of sentences in LKPD has been in accordance with the rules of the Indonesian language is good. Sentences are used to involve the ability to think logically learners because it has been adapted to the level of communication language learners. Thus, it can be concluded that LKPD has been valid from linguistic aspect. LKPD validation on aspects of chart or appearance is done by 1 lecturer of educational technology. The result of validity of chart aspect to LKPD is $75 \%$ with valid criteria. Thus, it can be concluded that LKPD has been valid from aspect of chart or display. The overall validity of LKPD is $88.75 \%$ with valid category. Thus it can be concluded LKPD based PBL is valid.

\section{d. One to one evaluation}

The revision of prototype I is prototype II, tested on 3 students to try to do LKPD which has been declared valid by the expert. The three students came from the class XI IPA 3 SMA Negeri 1 Pancung Problem which has different abilities, 1 learner with high ability, 1 learner with medium ability and 1 learner with medium ability. Each learner is asked to pay attention to the presentation of LKPD trying to work out LKPD according to their understanding of the problems, drawings, orders and questions in LKPD and asked to comment on LKPD. This individual evaluation was conducted on 6 LKPD. Activities undertaken are observing clues that are difficult for the learners to understand in LKPD, recording responses, suggestions, sentences that are difficult to understand and questions of learners about LKPD. Based on observations and interviews, revisions are made.

\section{e. Small Group Evaluation}

Small group evaluation on prototype III, tested to students of class XI IPA 3 SMA Negeri 1 Pancung Problem. In small group evaluation, learners consist of 8 students from high, medium and low ability. Eight students are divided into two groups with heterogeneous capabilities. Students are given valid and practical LKPD based on one to one evaluation stage. This small group evaluation was conducted six times.

Based on observations and interviews conducted on the learners found that in terms of time efficiency according to learners time to do LKPD is enough. Furthermore, in terms of implementation, learners are able to use LKPD quite easily, although there are still questions arising during working on LKPD.

The aspect of LKPD presentation has been interesting with the existence of problems in everyday life, even though initially learners feel difficult because rarely solve the story but learners look enthusiastic to try it. In the design section of the lesson according to the learners learning strategy using the problems related to daily life is quite interesting, his questions help learners solve problems and make conclusions. Activities at LKPD are interesting, the presentation of drawings and illustrations on LKPD makes it easy for them to understand the concept of the material they are learning.

\section{Assessment Phase}

The assessment phase is conducted to determine the effectiveness and effectiveness of Problem Based Learning LKPD that has been developed. The results of the practicality and effectiveness assessment of LKPD based on Problem Based Learning are as follows.

\section{a. Large Group Practices Test}

Large group test (field test) conducted in class XI IPA 2 SMA Negeri 1 Pancung Soal. Trial of learning based on Problem Based Learning was done 6 times meeting. During the test, the learning activities were observed by an observer. Observer in charge of observing the implementation of learning using the learning tools based on Problem Based Learning based on the observation sheet that has been provided.Practical data of LKPD based on Problem Based Learning is obtained from questionnaire of student response, teacher response questionnaire and observation of learning implementation. Questionnaire is given to all learners at the time of conducting a large group evaluation (Field Test). Questionnaires were given to 33 students. Questionnaire given after the learning process using LKPD based Problem Based Learning is completed. the average level of practicality of Problem Based Learning based LKPD according to the response of learners is $87.25 \%$. So, it can be concluded that LKPD based Problem Based Learning practically according to the response of learners. The average level of practicality of Problem Based Learning based LKPD according to teacher response is $90.28 \%$. So, it can be concluded that LKPD based on Problem Based Learning is very practical according to teacher response. The average level of practicality of implementation of learning activities based on Problem Based Learning based RPP is $90.99 \%$. So, it can be concluded that the learning tools based on Problem Based Learning is very practical based on the implementation of learning activities

\section{b. Effectiveness of Learning Tools Based on PBL}

The effectiveness of the mathematics learning device is seen from the final test results. The final test is given to the learners after the learning by using the learning tools based on Problem Based Learning mathematics in the form of 5 problem description problem solving. Results of data analysis of test results of problem solving ability of learners can be seen in the following table. 
TABLE I. RESULTS OF DATA ANALYSIS OF TEST RESULTS OF PROBLEM SOLVING ABILITY OF LEARNERS

\begin{tabular}{|c|c|c|c|}
\hline \multirow{2}{*}{} & \multicolumn{2}{|c|}{ Total Completion } & \multirow{2}{*}{ Total } \\
\cline { 2 - 3 } & $\begin{array}{c}\text { Completed } \\
(\geq 80)\end{array}$ & $\begin{array}{c}\text { Unfinished } \\
(<80)\end{array}$ & \\
\hline $\begin{array}{c}\text { Number of } \\
\text { Learners }\end{array}$ & 28 & 5 & 33 \\
\hline Percentage & $\mathbf{8 4 , 8 5}$ & 15,15 & 100 \\
\hline
\end{tabular}

From the table, it can be seen that the percentage of complete learners is $84,85 \%$ or $\geq 75 \%$. The number of students who took the final test is 33 people. The average value of the final test of the learner is 82.29. Based on the criteria of learning outcomes, the learning-based mathematical tool based on Problem Based Learning has been effective.

\section{CONCLUSION}

Based on the process and the result of the research, the following conclusions are obtained: The process of developing learning tools based on Problem Based Learning in the form of RPP and LKPD is done with the development model of Plomp which consists of three stages: preliminary research stage, development stage and assessment phase. The Problem Based Learning based learning tool generated from this research has met the valid, practical and effective product quality criteria

\section{REFERENCES}

[1] P. Mairing, Jackson, "Thinking Process Of Naïve Problem Solvers to Solve Mathematical Problem", International Education Studies, ISSN 1913-9020, EISSN 1913-9039, vol. 10, Accessed December 2016, 2014.

[2] Herman. Tatang, "Problem Based Learning To Improve Mathematical Reasoning Ability SMP Students", Educational Horizon. XXVI, 2007.

[3] Aka, I.I, Guven, E \& Aydogdu, "Effects of Problem Solving Method on Science Process Skills and Academic Achievement", Journal of Turkish Science Education, vol. 7, pp. 13-25, 2010.

[4] Volisa, Metra, Lely Kurnia and Zulmardi, "Development of RPP Mathematics with Problem Based Learning Boss Character Education In Material Dimension Three", Edusainstika, vol. 1, pp. 43-45, 2014.

[5] Utami. R, "Problem-Based Learning Model with Polya and Krulik-Rudnick Settlement Steps Viewed From Student Creativity", Journal of Scientific Mathematics Education, vol. 1, pp. 81-96, 2013.

[6] Pariska. Ike Suci, "Development of Problem-Based Mathematics Student Worksheet. Journal of Mathematics Education", vol. 1, pp. 75-80, 2012.

[7] Savery. J.R, "Overview of Problem Based Learning: Definitions and Distinctions", Interdisciplinary Journal of Problem-Based Learning, vol. 1, 2006.

[8] Plomp, T and N. Nieveen, "Educational Design Research", Enshede: Netherlands Institute For Curriculum Development (SLO), 2013. 